\title{
Covid-19 Pandemic Impacts on Essential Transit Riders: Findings from
}

\author{
a U.S. survey
}

Authors: Qian $\mathrm{He}^{1}$, Dana Rowangould ${ }^{*}$, Alex Karner ${ }^{3}$, Matthew Palm ${ }^{4}$, Seth Larue ${ }^{3}$

\section{Affiliations:}

${ }^{1}$ Department of Public Affairs and Planning, The University of Texas at Arlington; Arlington TX, USA

${ }^{2}$ Department of Civil and Environmental Engineering, University of Vermont; Burlington VT, USA

${ }^{3}$ Graduate Program in Community and Regional Planning, The University of Texas at Austin; Austin TX, USA

${ }^{4}$ Department of Urban Studies, Worcester State University; Worcester MA, USA

*Corresponding author. Email: dana.rowangould@uvm.edu

\begin{abstract}
:
The Covid-19 pandemic has decimated public transit service across the United States and caused significant decreases in ridership. Adapting to the pandemic has been more challenging for some transit riders than for others. Little is known about the reasons for pandemic-era mode shifts and the impacts of pandemic-related transit reductions on riders' day-to-day lives. Using a national survey of U.S. transit riders $(n=500)$, this study examines changes in transit use since the pandemic began, the reasons for transit reductions, and the effects of reduced transit use and
\end{abstract}


transit service on transit riders' ability to meet their travel needs. The Covid-19 pandemic has exacerbated existing transportation burdens for essential transit riders, pointing to shortcomings inherent in current transit financing policy. We close with recommendations for strengthening the transit service for these groups in the long term as we recover from the pandemic.

Keywords: Transportation Justice, Covid-19, Public Transit, Essential Transit Riders, Travel Behavior, Equity 


\section{INTRODUCTION}

The Covid-19 pandemic has decimated transit ridership across the United States. In the second quarter of 2020, subways, light rail, and commuter rail in the United States carried just $15 \%$ of the riders they did the year before; bus ridership dropped by two-thirds (Transit \& APTA, 2020a; Vock, 2020). These reductions in transit use are driven both by reductions in overall travel due to social distancing policies, as well as greater avoidance of transit travel due to concerns about Covid-19 exposure. As Covid-19 cases have stabilized in many parts of the US as of mid-2021 and immunization has accelerated, economic activity and day-to-day travel have gradually rebounded. However, diminished transit ridership persists.

In addition to plummeting ridership, transit agencies have also faced greater pandemic-related costs (EBP, 2021; Tirachini \& Cats, 2020). The combination of higher costs and reduced revenues has led to reduced transit service in communities across the U.S. Even after short-term funding relief provided by Congress, persistently low levels of ridership continue to threaten the financial viability of transit service (EBP, 2021) and transit agencies have laid plans for lasting cuts that are significantly larger than those enacted during the Great Recession that triggered the last ridership spiral (Boisjoly et al., 2018). For those who rely on transit, greatly diminished transit service will likely substantially reduce their ability to access critical destinations like work, groceries, health care, and education.

Recent work has evaluated Covid-19-related impacts on travel behavior and a subset of this analysis has focused on transit use, finding that areas with less pronounced ridership declines during the pandemic were more likely to be home to essential workers, low-income households, people of color, and women (Gartsman \& Prescott, 2021; Hu \& Chen, 2021; Liu et al., 2020). 
However, little is known about why travel adaptations to the pandemic have differed among and between different types of riders or about how the pandemic has affected different types of riders' mobility.

The impacts of pandemic-induced service cuts are likely to fall more heavily on those with few options. Several decades of transportation research point to two distinct types of transit passengers. For some, using public transit is a choice. These "choice" riders use transit but have access to other viable travel options. For a second group of riders, transit is essential, providing a critical lifeline, enabling access to jobs, schools, food, social services, recreation, and social connections needed to fulfill their day-to-day needs (Taylor \& Morris, 2015). This group of essential transit riders includes people who cannot obtain a license (e.g., youth, older adults, people with disabilities, and recent immigrants). It also includes those for whom driving or owning a car is prohibitively expensive. As transit service has declined during the pandemic, it is likely that those who rely on transit and those who have fewer travel options have suffered greater burdens than those with alternative travel options.

To better understand the effects of the pandemic on different types of riders, we conducted a survey of U.S. public transit users in fall $2020(n=500)$. Riders were recruited using multiple methods, with most responses coming from social media ads and posts. Our sample captures several key dimensions of U. S. transit riders, providing insights into differences in pandemicrelated transit impacts on different types of riders. We examine the impacts of the pandemic on different groups by assessing respondents' self-reported changes in transit use during the pandemic, reasons for reducing transit use, and difficulty reaching essential destinations for those who reduced their transit use. 
We find that transit riders without access to private vehicles and riders who report that they rely on transit to meet their travel needs were less likely to reduce their use of transit during the pandemic. Those who are more likely to report using transit during the pandemic include riders without access to private vehicle, riders who rely on transit, Hispanic or Latinx riders, female ${ }^{1}$ riders, and riders with low incomes.

For those who reduced or stopped using public transit, the reasons for reductions vary across different types of riders. Hispanic and Latinx transit riders are significantly more likely to report that they reduced their transit use due to transit service changes, moving, and the expense of transit trips when controlling all other factors. They were also more likely to report that concerns about interactions with law enforcement deterred transit use. Among riders who report reducing their transit use, those who rely on transit and socially vulnerable riders are more likely to experience significantly greater difficulty accessing essential destinations (work, groceries, healthcare, pharmacy, family care, and childcare).

\footnotetext{
${ }^{1}$ Our survey's gender question included options for "male", "female", and an open-ended text response option. 16 respondents used the text box to indicate non-male and non-female gender identities including non-binary and other identities. Due to the small sample size for this gender category we grouped these respondents with the "female" category in our analysis in order to retain their responses. Since we were unable to test for the relationships associated with nonbinary gender group in our models separately, we refrain from discussing the results in terms of a nonbinary gender category and instead refer only to findings for "female" respondents.
} 
The findings of this study characterize the impact of Covid-19 on transit riders on essential transit riders, pointing to policy recommendations that can strengthen transit service for these groups as we recover from the pandemic.

\section{LITERATURE REVIEW}

Transportation systems provide essential links between people and the opportunities they value. This connection is captured in the concept of accessibility—or the ease with which destinations can be reached (Handy, 2020; Levine et al., 2019; Martens, 2012; Martens et al., 2012). Prior work has demonstrated that accessibility is not equitably distributed across population groups or space (Allen \& Farber, 2019; Grengs, 2015; Karner, 2018). Instead, one's level of access is determined by mode availability, transportation infrastructure conditions, modal levels of service, and socioeconomic conditions like income and age (Cochran, 2020; Kwan, 2013; Shamshiripour et al., 2020).

Movements for transportation equity, transportation justice, and mobility justice in principle seek similar goals - ensuring that transportation systems enable access to opportunities for vulnerable groups - but they differ in their conceptual roots, their characterization of the causes of inequities, and in their proposed remedies (Karner et al., 2020; Sheller, 2018; Verlinghieri \& Schwanen, 2020). For example, public agencies often use transportation equity framings and are motivated to act by legal requirements or guidelines that call for quantitative analysis of plan and project impacts (Karner \& Levine, In press; Karner \& Niemeier, 2013). On the other hand, activists and advocates more often use transportation and mobility justice frameworks to argue for more radical changes in decision making priorities and funding allocations (Verlinghieri, 2019). 
Mobility justice perspectives that stem from both humanities scholarship and the experiences of Black, Indigenous, and people of color (BIPOC) transportation professionals require examining a much broader and multi-scalar set of considerations to achieve justice (Sheller, 2018; Untokening Collective, 2017). This includes elevating the lived experiences of BIPOC communities and individuals rather than defining populations based on what they lack, challenging historic and ongoing systemic racism that reinforces and perpetuates inequities, centering the perspectives of people of color in decision-making, and looking globally at the forces perpetuating automobile dependence, like the fossil fuel industry. When applied to accessibility, a mobility justice-informed emphasis on travelers' identity points to shortcomings in traditional notions of access to opportunities that have focused on transportation and land use systems and infrastructure rather than people and their unique and varied lived experiences. Accessibility is affected by many factors not commonly studied including perceived and actual safety, the presence of law enforcement, immigration status, gender presentation, race/ethnicity, and disability status (e.g., Church \& Marston, 2003; Loukaitou-Sideris, 2014; Lubitow et al., 2017, 2020). The focus on lived experience acknowledges the differences in transportation patterns between groups. For instance, gender socialization and inequities have well established effects on travel patterns with women taking on a greater share of household-serving trips including those related to child care (Taylor et al., 2015). These patterns are additionally shaped by overlapping identities such as class and ethnicity (Gilow, 2020; Matsuo, 2020). These differences mean that access is experienced differently based on individual and social characteristics. 
It is clear from each of these distinct but related frameworks that disparities in transportation access are deeply problematic. Indeed, the confluence of poor transportation resources and low access can lead to transportation-related social exclusion in which individual activity participation is curtailed and it becomes difficult to engage in the activities needed to lead a meaningful life, leading to impacts on health and quality of life (Duvarci et al., 2015; Lucas, 2012; Ryvicker et al., 2020). Those relying on public transit for most or all trips are at particular risk in the U.S. since transit service is often infrequent and inconvenient. Poor service for these riders is the norm, while transit agency budgets are often devoted to pursuing "choice riders"those with the ability to choose driving for most trips (Grengs, 2005; Taylor \& Morris, 2015). But it is those who rely on transit who are the core constituency whose revenue drives service. The Covid-19 pandemic has undoubtedly put these riders at a heightened risk of injustice and exclusion by placing public transit agencies in a precarious funding position (Tirachini \& Cats, 2020). In the aftermath of the lockdowns that began in March 2020, public transit ridership and fare revenues declined precipitously (Hu \& Chen, 2021; Liu et al., 2020). Transit agencies had to allocate resources to enhanced cleaning protocols and many suspended fare collection to minimize interactions between riders and operators (Tirachini \& Cats, 2020). Because of the nature of public transit— with passengers sharing space in close proximity—ridership has not recovered. A year after pandemic lockdowns began, transit ridership has returned to just $50 \%$ of pre-pandemic levels (Transit \& APTA, 2020b) even as vehicle travel fully recovered (BTS, n.d.). Returning service and ridership to pre-pandemic levels and safeguarding essential transit service will require overcoming structural financing shortcomings and investments at multiple levels. Historically, transit agencies have prioritized investments in more expensive rail service that 
serves wealthier White "choice" riders commuting to downtowns at the expense of bus service that provides a lifeline for vulnerable riders (Taylor \& Morris, 2015). This imbalance in transit funding priorities can be attributed to misaligned incentives rooted in the need to obtain significant levels of subsidy on top of fare revenue, which often cover only a small share of transit operating and capital expenses (Taylor \& Morris, 2015). Federal funding generally supports large capital improvements like rail infrastructure. These investments have historically been justified using optimistic ridership projections that fail to materialize (Voulgaris, 2020). They then require operation and maintenance funding, which may come at the expense of bus service. Intra-regional competition for these funds often means that low-income communities with lower civic or advocacy capacity are less likely to receive funding (Lowe et al., 2016). The mechanisms of federal funding and regional transportation planning through Metropolitan Planning Organizations (MPO) have clearly stated equity requirements, but funding decisions at the state and local level can bypass projects with an equity focus or introduce regressive funding mechanisms that lessen the positive impacts (Lowe, 2014; Lowe \& Hall, 2019). Avoiding these mistakes and understanding how best to use available funds for those most in need is essential in moving forward.

The pandemic's effects on socially vulnerable populations and those with fewer travel options has highlighted the different experiences and needs of essential riders in a time of disruption, pointing to the importance of addressing these structural transit funding shortcomings to ensure that transit systems remain resilient and adequately serve those who rely on them in the short and long-term. It is already clear that the mobility challenges presented by Covid-19 fell harder on groups who have already been marginally served by transportation systems, reflecting broader 
societal disparities (e.g., Adams-Prassl et al., 2020). In multiple studies, seniors and riders with disabilities reported that many agency responses to the pandemic, such as backdoor boarding, made it more difficult to use public transit (Cochran, 2020; Ravensbergen \& Newbold, 2020). Among riders avoiding transit in Canada, women, people with disabilities, and those with chronic health problems were more likely to experience difficulty accessing essential destinations (Palm et al., 2021). Digital alternatives to essential travel, such as online grocery shopping and app-based food delivery, did not universally ameliorate these problems. Lowincome and Hispanic/Latinx households in Portland, Oregon, were significantly less likely to have food delivered to their homes during the pandemic (Figliozzi \& Unnikrishnan, 2021). Evidence from Chicago suggests that lower income residents saw the greatest increases in spending on groceries, with researchers suggesting that the inability to travel forced many lowincome riders to shop at more expensive local stores (Shamshiripour et al., 2020). Additionally, telecommuting ability has also been a stark dividing line, with those able to work from home more likely to maintain employment and earning status (Adams-Prassl et al., 2020).

Although previous research has provided an indication of the populations that have remained on transit (Gartsman \& Prescott, 2021; Hu \& Chen, 2021; Liu et al., 2020), little is known about why travel adaptations to the pandemic have differed among and between different types of riders or about how the pandemic has affected different types of riders' ability to get around. Although there has been a survey has evaluated pandemic-related mobility patterns and changes among highly educated travelers in the U.S. (Conway et al., 2020), to date, no surveys have focused on Covid-related impacts on transit use and transit riders' lived experiences in the U.S. context. To understand the equity and justice implications of changing public transit service 
levels on essential transit riders, we conducted a nationwide survey of public transit users during the Covid-19 pandemic. Understanding differences in the effects of the pandemic on different types of transit riders' mobility can inform how we recover from the current pandemic-related funding crisis. These insights also point to the need protect essential transit service and strengthen transit service financing models in the long term.

\section{DATA AND METHODS}

\section{Survey Design and Sampling}

In fall 2020, we conducted a nationwide online survey of nearly 500 people who indicated that they used transit at least once per week for part or all of 2020. The survey built on a similar instrument implemented in Toronto and Vancouver, Canada (Palm et al., 2021) and included questions about:

- travel behavior before and during the pandemic including transit mode, frequency of transit trips, and self-reported changes in transit use,

- individual and household characteristics including race, ethnicity, vehicle ownership, monthly income, disability, age, driver's license, and residential location,

- attitudes about public transit and Covid-19 including reliance on transit to meet daily travel needs and reasons for reducing transit, and

- self-reported difficulty reaching essential destinations.

The survey was conducted in English and Spanish through Qualtrics, an online survey platform, from 9/17/2020 through 11/20/2020. Respondents were recruited using six methods: Facebook ads, posts to transit-related Facebook groups, posts on transit-related subreddits (Reddit topics), 
emails to transit advocacy groups, and a link that could be shared by respondents. We excluded responses that incorrectly selected the answer for either of two filter questions that asked respondents to select a particular response to screen out those who were clicking without reading the survey prompts. Out of 898 total responses, 500 are usable in this analysis, with over $85 \%$ of these recruited through Facebook ads and Reddit.

We compare our survey respondents to the population of U.S. transit riders, as estimated using the weighted subsample of 2017 National Household Travel Survey respondents who are over 18 and reported using transit at least once in the past 30 days (Table 1). Overall, our survey is relatively consistent with U.S. transit riders in terms of many of the characteristics examined, although our sample skews toward transit riders that are young, middle income, White, male, and do not have vehicle access. Because our survey instrument is internet based, it likely overrepresents respondents with internet access at home or on mobile devices and underrepresents transit riders without internet access. Additional detail about the survey methods and respondent characteristics is included in the supplementary material. Because we are estimating statistical models and comparing results between groups in our sample rather than estimating population characteristics, the sampling strategy is appropriate (Zhang et al., 2020). 
Table 1: Characteristics of survey respondents and U.S. transit riders.

\begin{tabular}{|c|c|c|}
\hline & Survey respondents & U.S. transit riders \\
\hline Age $(n=$ people $)$ & 494 & $39,766,841$ \\
\hline $18-29$ & $39 \%$ & $25 \%$ \\
\hline $30-49$ & $40 \%$ & $37 \%$ \\
\hline $50-69$ & $20 \%$ & $31 \%$ \\
\hline $70+$ & $1 \%$ & $7 \%$ \\
\hline Annual pre-tax income $(n=$ people $)$ & 499 & $38,771,955$ \\
\hline Less than $\$ 14,999$ & $20 \%$ & $20 \%$ \\
\hline$\$ 15,000$ to $\$ 34,999$ & $20 \%$ & $17 \%$ \\
\hline$\$ 35,000$ to $\$ 74,999$ & $31 \%$ & $20 \%$ \\
\hline$\$ 75,000$ to $\$ 124,999$ & $16 \%$ & $19 \%$ \\
\hline$\$ 125,000$ or more & $14 \%$ & $24 \%$ \\
\hline Race and Ethnicity $(n=$ people $)$ & 500 & $39,643,219$ \\
\hline Non-Hisp American Indian or Alaska Native & $0.2 \%$ & $0.4 \%$ \\
\hline Non-Hisp Asian & $6 \%$ & $9 \%$ \\
\hline Non-Hisp Black & $6 \%$ & $19 \%$ \\
\hline Non-Hisp Other & $3 \%$ & $1 \%$ \\
\hline Non-Hisp White & $63 \%$ & $49 \%$ \\
\hline Non-Hisp Multiple Races & $2 \%$ & $2 \%$ \\
\hline Hispanic or Latinx & $19 \%$ & $19 \%$ \\
\hline Gender $(n=$ people $)$ & 495 & $36,697,170$ \\
\hline Female & $40 \%$ & $52 \%$ \\
\hline Male & $56 \%$ & $48 \%$ \\
\hline Non-binary or other gender identity & $3 \%$ & -- \\
\hline Vehicle access $*(n=$ people $)$ & 496 & $39,766,841$ \\
\hline Owns car & $36 \%$ & \multirow{2}{*}{$72 \%$} \\
\hline Can borrow a car & $21 \%$ & \\
\hline Carshare & $6 \%$ & $3 \%$ \\
\hline No vehicle access & $43 \%$ & $26 \%$ \\
\hline Transit mode* $(\mathrm{n}=$ trips $)$ & 7,423 & $25,029,138$ \\
\hline Bus & $53 \%$ & $52 \%$ \\
\hline Light rail & $34 \%$ & $34 \%$ \\
\hline Heavy rail & $7 \%$ & $8 \%$ \\
\hline Other & $5 \%$ & $6 \%$ \\
\hline
\end{tabular}

* Survey respondents could select multiple responses to vehicle access and mode questions, so columns sum to more than $100 \%$. 


\section{Research Framework and Modelling Approach}

This study evaluates three research questions:

1. How has the Covid-19 pandemic affected transit use among different types of transit riders?

2. For riders who have reduced or stopped transit use, how do their reasons for stopping or reducing transit use differ across different types of riders?

3. For riders who have reduced or stopped transit use, how does the difficulty accessing essential destinations in life (work, grocery, healthcare, pharmacy, family care, and childcare) posed by reduced transit use vary across different types of riders?

To address the first question, we evaluated both current transit use (number of trips conducted by all modes of public transit last week during the pandemic, including bus, light rail, heavy rail, paratransit, and other modes) and the change in transit use during the Covid-19 pandemic (whether a rider reported reducing or stopping their use of transit). We use a negative binomial model to evaluate the relationship between rider characteristics and current transit use. Due to the non-normal distribution of the dependent variable and the nature of the magnitude of the mean value, which is smaller than the standard error, a negative binomial model formulation is a better option than Poisson regression. We used logistic models to evaluate the likelihood that different rider types have chosen to reduce or stop transit use given the binary nature of the dependent variable modeled, which is formulated as "reduce or stop transit use" or "no change or increase in transit use."

To evaluate the second research question, we use responses to questions that asked those who reduced or stopped using transit to rate how important each of several reasons was in their 
decision to reduce their transit use. Reasons include no longer going to destinations that they would use transit to reach, concerns about the risk of exposure to Covid-19, changes in transit service, the expense of transit trip, relocating during the pandemic, and concerns about experiencing harassment or interacting with police or Immigration and Customs Enforcement (ICE).

We examine the third research question using responses to questions that asked the subset of riders who reduced or stopped their transit use to indicate the extent to which those reductions made it harder to reach several essential destinations, including work, groceries, healthcare, prescriptions, caring for family and friends, and taking children to childcare.

Scaled outcomes are recoded as binary variables for use in multivariate models. Responses describing how important each reason was in deciding to reduce or stop transit use are recoded as "not important" (including "not important" and "not applicable") and "important" ("a little important", "somewhat important" and "very important"). For the question about whether it was harder to reach destinations, "not harder at all" is recoded as "not harder", while "a little harder", "somewhat harder" and "much harder" are recoded as "harder", and "not applicable" responses are excluded. We also retain the full list of ordered responses for evaluations of between-group differences using Wilcoxon-Mann-Whitney tests.

We evaluate each of the three research questions using individual demographic characteristics (Hispanic/Latinx, physical disability, poverty status, income reduction, age, and gender). For the gender category we group female responses with respondents that indicated a non-binary or other gender description in an open text response (3.2\% of respondents). We also evaluate mobility characteristics (vehicle access, driver's license, rely on transit). The transit reliance variable was 
based on responses to the prompt "I rely on public transit to meet my essential travel needs", where "agree" and "strongly agree" were coded as 1 for "rely on transit" and "strongly disagree", "disagree", and "neither agree nor disagree" were coded as 0 , while "not applicable" is omitted. We also construct a set of binary variables for the transit mode(s) most frequently used before the Covid-19 pandemic, with ties receiving a 1 for each mode. For example, a person riding the bus four times per week and rail four times per week is coded as a bus rider and a rail rider, whereas a person riding the bus four times per week and rail twice per week is coded as a bus rider. We also control for zip code-level population density and county-level cumulative number of Covid-19 infection cases. Population density is based on the 2018 American Community Survey 5-year estimates of the number of people living in the respondent's ZCTA area (U.S. Census Bureau, n.d.). Cumulative infections are based on positive Covid-19 cases reported in the respondent's county since the beginning of the pandemic (1/22/2020) up to the respondent's survey date using infection data from Johns Hopkins University (Dong et al., 2020). Summary statistics for all modeled variables are included in Table 2.

We also conduct Wilcoxon-Mann-Whitney tests to evaluate the statistical significance of differences between groups of essential riders who reduced their transit use in terms of their ability to reach two types of essential destinations: care for family, and childcare. These two destination types had smaller sample sizes that precluded multivariate modeling but are relevant for understanding the ability to undertake caretaking activities. We evaluate differences in these outcomes for riders without vehicle access, riders without a driver's license, those who rely on transit, Hispanic and Latinx riders, riders with a physical disability, female riders, and riders living below twice the poverty level. 
Table 2: Summary of modeled variables.

\begin{tabular}{|c|c|c|c|c|c|c|}
\hline Variable & Data Description & $\mathbf{N}$ & Mean & St. dev. & Min & Max \\
\hline $\begin{array}{l}\text { Number of weekly transit trips (during } \\
\text { pandemic) }\end{array}$ & Count data & 500 & 7.19 & 10.51 & 0 & 96 \\
\hline $\begin{array}{l}\text { Cumulative Covid-19 infections since } \\
\text { pandemic began (Log) }\end{array}$ & Continuous data & 487 & 14.76 & 1.46 & 7.27 & 17.30 \\
\hline $\begin{array}{l}\text { Population density (households/square } \\
\text { meters) }\end{array}$ & Continuous data & 487 & 0.01 & 0.01 & $4.22 \mathrm{e}-07$ & 0.06 \\
\hline Reduced transit use & $1=$ Reduced $/$ stopped using transit $(n=355)$ & 500 & 0.71 & 0.45 & 0 & 1 \\
\hline Driver's license & $1=$ Have driver's license $(\mathrm{n}=356)$ & 500 & 0.71 & 0.45 & 0 & 1 \\
\hline Vehicle access & $1=$ Have access to a vehicle $(n=291)$ & 499 & 0.58 & 0.49 & 0 & 1 \\
\hline Rely on transit & $1=$ Rely on transit $(n=318)$ & 499 & 0.64 & 0.48 & 0 & 1 \\
\hline Hispanic/Latinx & $1=$ Hispanic or Latinx $(\mathrm{n}=100)$ & 417 & 0.24 & 0.43 & 0 & 1 \\
\hline Female and non-binary & $1=$ Female and non-binary Gender $(n=217)$ & 496 & 0.44 & 0.50 & 0 & 1 \\
\hline Disability & $1=$ Have a physical disability $(n=11)$ & 452 & 0.02 & 0.15 & 0 & 1 \\
\hline Poverty status (before pandemic) & $1=$ Below twice poverty threshold $(n=193)$ & 500 & 0.39 & 0.49 & 0 & 1 \\
\hline Reduced income & $1=$ Household income has reduced $(n=198)$ & 474 & 0.42 & 0.49 & 0 & 1 \\
\hline Bus user (before pandemic) & $1=$ Bus is most frequently used transit mode & 500 & 0.67 & 0.47 & 0 & 1 \\
\hline Rail user (before pandemic) & $1=$ Rail is most frequently used transit mode & 500 & 0.44 & 0.50 & 0 & 1 \\
\hline Other transit user (before pandemic) & $1=$ Other most frequently used transit mode & 500 & 0.04 & 0.19 & 0 & 1 \\
\hline \multirow[t]{4}{*}{ Age group } & $1=24$ years or younger $(n=100)$ & 494 & - & - & - & - \\
\hline & $2=$ Between $25-44$ years old $(n=260)$ & & & & & \\
\hline & $3=$ Between $45-64$ years old $(n=114)$ & & & & & \\
\hline & $4=65$ years or older $(n=20)$ & & & & & \\
\hline
\end{tabular}




\section{Results and Discussion}

We first evaluate how the Covid-19 pandemic has affected transit user among different types of transit riders. Results from the negative binomial model of trips taken last week during the pandemic are summarized in Table 3. Higher trip counts are associated with transit riders who do not have access to a vehicle, indicate that they rely on transit to meet their needs, and those living below twice the poverty level. Hispanic and Latinx and male transit riders are also more likely to use transit more frequently. Additionally, public transit use prior to the pandemic is associated with higher trip counts during the pandemic. We also find that people without access to a vehicle and those who reported that they rely on transit are less likely to reduce or stop using transit (Table 4).

These findings are consistent with prior literature on essential riders, independent of the pandemic. Their travel persists regardless of other contextual factors, as both population density and local Covid-19 rates yield no significant effects. In short, reducing or ceasing public transit use is not an option for all riders. Riders with vehicle access have a readily available alternative to public transit. Under pandemic conditions, that alternative likely became very attractive as a means to achieve social distancing. Those reporting that they rely on public transit to meet their needs may have only sporadic access to other modes, attitudes that support public transit use, or access to a level of service that meets their needs. Finally, higher-income transit users are more likely to have jobs conducive to telecommuting and/or working from home, allowing them to eliminate their commute. 
Table 3: Negative binomial model of number of transit trips last week.

\begin{tabular}{|c|c|c|c|}
\hline Variable & Coef. & Robust St. Err. & P-value \\
\hline \multicolumn{4}{|c|}{$\begin{array}{l}\text { Dependent Variable: Count } \\
\text { (\# weekly transit trips during the pandemic) }\end{array}$} \\
\hline Vehicle access (1) & -0.56 & 0.14 & $<0.001 * * *$ \\
\hline Rely on transit (1) & 1.28 & 0.19 & $<0.001 * * *$ \\
\hline Hispanic/Latinx (1) & 0.47 & 0.18 & $0.010 * * *$ \\
\hline Disability (1) & 0.37 & 0.36 & 0.307 \\
\hline Female (1) & -0.49 & 0.16 & $0.002 * * *$ \\
\hline Poverty status (1) & 0.37 & 0.15 & $0.018 * *$ \\
\hline \multicolumn{4}{|l|}{ Age (reference $<25$ yrs) } \\
\hline $25-44$ years old $(2)$ & 0.11 & 0.16 & 0.496 \\
\hline 45-64 years old (3) & 0.30 & 0.20 & 0.119 \\
\hline 65 years and older $(4)$ & 0.18 & 0.49 & 0.717 \\
\hline \multicolumn{4}{|l|}{ Transit mode used most often } \\
\hline Bus (1) & 0.70 & 0.23 & $0.002 * * *$ \\
\hline Rail (1) & 0.62 & 0.23 & $0.007 * * *$ \\
\hline Others (1) & 1.25 & 0.40 & $0.002 * * *$ \\
\hline Population density & 7.05 & 8.52 & 0.408 \\
\hline Cumulative Covid-19 infection (Log) & 0.07 & 0.05 & 0.224 \\
\hline Constant & -0.94 & 0.81 & 0.244 \\
\hline /lnalpha & 0.46 & 0.11 & \\
\hline alpha & 1.58 & 0.17 & \\
\hline \multicolumn{4}{|c|}{ Number of Observations $=371 ;$ Wald Chi2 $(14)=159.84$} \\
\hline \multicolumn{4}{|c|}{ Prob $>$ Chi2 $=0.000 ;$ Log pseudolikelihood $=--975.15076 ;$ Pseudo R2 $=0.0608$} \\
\hline
\end{tabular}

Next, we examine the reasons that some riders reduced or stopped using transit. Table 5 includes results from eight logistic regression models examining the reasons for reducing or stopping transit use for different groups of transit riders among those who reported doing so. The results indicate that transit riders with access to a vehicle are less likely to reduce their transit use because they no longer need to travel to the same destinations but are more likely to be dissuaded by fare costs. Those who report relying on transit are less likely to cite a move as a reason for reducing their transit use. 


\section{Table 4: Logistic model of reduction in public transit use during the Covid-19 pandemic}

\begin{tabular}{|c|c|c|c|}
\hline Variable & Odds Ratio & Robust St. Err. & P-value \\
\hline \multicolumn{4}{|l|}{$\begin{array}{l}\text { Dependent Variable: } \\
\text { Reduced transit use-1, Otherwise -0 }\end{array}$} \\
\hline Vehicle access (1) & 1.79 & 0.51 & $0.040 * *$ \\
\hline Rely on transit (1) & 0.35 & 0.11 & $0.001 * * *$ \\
\hline Hispanic/Latinx (1) & 1.00 & 0.29 & 0.995 \\
\hline Disability (1) & 0.36 & 0.27 & 0.168 \\
\hline Female (1) & 1.07 & 0.28 & 0.795 \\
\hline Poverty status (1) & 0.61 & 0.16 & 0.063 \\
\hline \multicolumn{4}{|l|}{ Age (reference $<25$ yrs) } \\
\hline $25-44$ years old $(2)$ & 1.06 & 0.35 & 0.853 \\
\hline $45-64$ years old (3) & 0.71 & 0.27 & 0.378 \\
\hline 65 years and older $(4)$ & 2.81 & 2.9 & 0.317 \\
\hline \multicolumn{4}{|l|}{ Transit mode used most often } \\
\hline Bus (1) & 1.20 & 0.48 & 0.649 \\
\hline Rail (1) & 1.09 & 0.43 & 0.826 \\
\hline Other (1) & 1.42 & 0.94 & 0.593 \\
\hline Population density & $1,818,666$ & $28,200,000$ & 0.353 \\
\hline Cumulative Covid-19 Infection (Log) & 0.98 & 0.09 & 0.857 \\
\hline Constant & 5.05 & 7.60 & 0.282 \\
\hline \multicolumn{4}{|c|}{$\begin{array}{l}\text { Number of Observation }=371 ; \text { Wald Chi } 2(14)=32.94 ; \text { Prob }>\text { Chi } 2=0.0029 \\
\text { Log Pseudolikelihood }=-194.29404 . \text { Pseudo } 22=.0972\end{array}$} \\
\hline
\end{tabular}

Hispanic and Latinx riders who reduce their transit use are less likely to cite a change in needing to travel to the same destinations and more likely to cite a move, a change in transit service, the cost of riding transit, and concerns about harassment or interactions with police or ICE on transit. Female respondents are more likely to cite concern about harassment as a reason for reducing their transit use. Transit riders living below twice the poverty level are more likely to cite the risk of contracting Covid-19 and a move, while those whose income was reduced are more likely to cite a change in transit service, the cost of using transit, and concerns about harassment. Concerns about harassment and interactions with police and ICE may be greater during the pandemic in areas where reduced ridership means that transit vehicles are less crowded, leading to greater feelings of isolation and vulnerability for those remaining. The pandemic has also coincided with growing concerns about racial justice and treatment of people of color by law 
enforcement spurred on by the murders of George Floyd, Brianna Taylor, and several other people of color in 2020 .

Younger transit riders are more likely to cite a change in the need to travel to the same destination and less likely to cite a move, while older riders are less likely to cite the risk of Covid-19 on transit as a reason for reducing their transit use. The surprising age results mirror findings from Canada (Palm et al., 2021), and likely reflect the sampling frame of regular transit users. While seniors may be less likely to ride transit among the general population, seniors who rode transit regularly before Covid-19 may depend on the service more than working-age people using the mode to commute. Transit riders living in more densely populated areas are also less likely to cite exposure to Covid-19 as a reason for reducing their use of transit.

Together, these results demonstrate dramatically different effects of the Covid-19 pandemic on the travel behavior of different groups of riders. Some of these echo extant findings in the literature, like the differential experiences of harassment and threat faced by women and people of color while traveling in public spaces (Loukaitou-Sideris, 2014; Lubitow et al., 2019). But others are more novel, including the effects of service changes on different groups. In addition to disparities in the baseline levels of service and accessibility afforded to different groups, the results reported here suggest that public transit service cuts implemented as a necessity by fiscally constrained agencies may have had an outsized effect on travel behavior for Hispanic and Latinx riders and those who suffered a loss of income from the pandemic. There is overlap between the reasons for transit reductions, but given sample size constraints, it is not possible to account for them simultaneously in a multivariate modeling framework. 
We also evaluate the effects of pandemic-related transit use reductions on riders' mobility. For many transit riders ceasing or reducing public transit use is not benign; among riders using transit less or not at all during the pandemic, we again found differential impacts based on their characteristics (Table 6). People who rely on transit to meet their needs and vulnerable populations (including Hispanic or Latinx, female, and low-income riders) are more likely to report greater difficulty accessing important destinations, and in particular healthcare. As one respondent without access to a car put it in response to an open-ended survey prompt, "transit is my lifeline to appointments and getting around." Again, these results reinforce the impacts of Covid-19's broad economic and transportation-specific impacts on essential public transit users. 
Table 5: Logistic models of the reasons for reducing transit use (for those who reduced or stopped using transit)

\begin{tabular}{|c|c|c|c|c|c|c|c|c|c|c|c|c|c|c|c|c|}
\hline & \multirow{2}{*}{\multicolumn{2}{|c|}{$\begin{array}{c}\text { Model 1 } \\
\begin{array}{c}\text { No longer going to } \\
\text { destination }\end{array}\end{array}$}} & \multirow{2}{*}{\multicolumn{2}{|c|}{$\begin{array}{c}\text { Model 2 } \\
\text { Concern about } \\
\text { Covid-19 infection }\end{array}$}} & \multirow{2}{*}{\multicolumn{2}{|c|}{\begin{tabular}{|c|} 
Model 3 \\
Move residence
\end{tabular}}} & \multirow{2}{*}{\multicolumn{2}{|c|}{$\begin{array}{c}\text { Model } 4 \\
\begin{array}{c}\text { Transit service } \\
\text { change }\end{array}\end{array}$}} & \multirow{2}{*}{\multicolumn{2}{|c|}{$\begin{array}{c}\text { Model 5 } \\
\text { Expense of } \\
\text { public transit }\end{array}$}} & \multirow{2}{*}{\multicolumn{2}{|c|}{$\begin{array}{c}\text { Model 6 } \\
\text { Concern about } \\
\text { harassment }\end{array}$}} & \multirow{2}{*}{\multicolumn{2}{|c|}{$\begin{array}{c}\text { Model 7 } \\
\begin{array}{c}\text { Concern about } \\
\text { police }\end{array}\end{array}$}} & \multicolumn{2}{|c|}{ Model 8} \\
\hline & & & & & & & & & & & & & & & Concer & about ICE \\
\hline & $\begin{array}{l}\text { Odds } \\
\text { Ratio }\end{array}$ & $\begin{array}{l}\text { Robust } \\
\text { St. Err. }\end{array}$ & $\begin{array}{l}\text { Odds } \\
\text { Ratio }\end{array}$ & $\begin{array}{l}\text { Robust } \\
\text { St. Err. }\end{array}$ & $\begin{array}{l}\text { Odds } \\
\text { Ratio }\end{array}$ & $\begin{array}{l}\text { Robust } \\
\text { St. Err. }\end{array}$ & $\begin{array}{l}\text { Odds } \\
\text { Ratio }\end{array}$ & $\begin{array}{l}\text { Robust } \\
\text { St. Err. }\end{array}$ & $\begin{array}{l}\text { Odds } \\
\text { Ratio }\end{array}$ & $\begin{array}{l}\text { Robust } \\
\text { St. Err. }\end{array}$ & $\begin{array}{l}\text { Odds } \\
\text { Ratio }\end{array}$ & $\begin{array}{l}\text { Robust St. } \\
\text { Err. }\end{array}$ & $\begin{array}{l}\text { Odds } \\
\text { Ratio }\end{array}$ & $\begin{array}{l}\text { Robust } \\
\text { St. Err. }\end{array}$ & $\begin{array}{l}\text { Odds } \\
\text { Ratio }\end{array}$ & $\begin{array}{l}\text { Robust St. } \\
\text { Err. }\end{array}$ \\
\hline Dependent Variable: & Vot import & t; 1-Impol & ant) & & & & & & & & & & & & & \\
\hline Vehicle Access (1) & $\begin{array}{l}0.47 \\
(* *)\end{array}$ & 0.18 & 0.86 & 0.52 & 1.51 & 0.71 & 1.46 & 0.44 & $\begin{array}{l}2.37 \\
(* *)\end{array}$ & 1.03 & 1.00 & 0.30 & 1.36 & 0.46 & 1.95 & 1.08 \\
\hline Rely on transit (1) & 0.99 & 0.36 & 0.36 & 0.22 & $\begin{array}{l}\mathbf{0 . 3 9} \\
(* *) \\
\end{array}$ & 0.18 & 1.19 & 0.38 & 0.95 & 0.39 & 1.045 & 0.34 & 1.34 & 0.45 & 0.94 & 0.51 \\
\hline Hispanic/Latinx (1) & $\begin{array}{c}\mathbf{0 . 3 3} \\
(* * *)\end{array}$ & 0.13 & 0.70 & 0.44 & $\begin{array}{l}2.49 \\
(* *)\end{array}$ & 0.96 & $\begin{array}{l}2.08 \\
(* *)\end{array}$ & 0.67 & $\begin{array}{l}10.68 \\
(* * *)\end{array}$ & 4.49 & $\begin{array}{c}2.37 \\
(* * *)\end{array}$ & 0.75 & $\begin{array}{c}\mathbf{3 . 0 8} \\
(* * *)\end{array}$ & 1.038 & $\begin{array}{l}5.04 \\
(* * *)\end{array}$ & 2.50 \\
\hline Female (1) & 1.25 & 0.50 & 1.72 & 1.06 & 1.12 & 0.38 & 0.82 & 0.22 & 1.98 & 0.75 & $\begin{array}{l}1.89 \\
(* *)\end{array}$ & 0.51 & 1.34 & 0.41 & 1.47 & 0.71 \\
\hline Poverty status (1) & 0.56 & 0.22 & $\begin{array}{c}7.27 \\
(* *)\end{array}$ & 6.39 & $\begin{array}{c}3.30 \\
(* * *)\end{array}$ & 1.31 & 1.20 & 0.35 & 1.68 & 0.67 & 1.24 & 0.37 & 1.03 & 0.33 & 1.61 & 0.78 \\
\hline Income reduced (1) & 1.21 & 0.49 & 1.03 & 0.56 & 1.52 & 0.52 & $\begin{array}{l}1.96 \\
(* *)\end{array}$ & 0.52 & $\begin{array}{c}2.83 \\
(* * *)\end{array}$ & 1.03 & $\begin{array}{l}1.83 \\
(* *)\end{array}$ & 0.50 & 1.30 & 0.40 & 1.16 & 0.60 \\
\hline Age $($ reference $<25)$ & & & & & & & & & & & & & & & & \\
\hline $25-44$ years old $(2)$ & $\begin{array}{l}2.06 \\
(* *)\end{array}$ & 0.85 & 1.22 & 0.87 & $\begin{array}{l}0.38 \\
(* *)\end{array}$ & 0.16 & 0.53 & 0.17 & 0.43 & 0.21 & 0.78 & 0.27 & 0.86 & 0.31 & 1.97 & 1.15 \\
\hline 45-64 years old (3) & 1.65 & 0.91 & 0.75 & 0.58 & $\begin{array}{l}0.37 \\
(* *) \\
\end{array}$ & 0.20 & 0.71 & 0.29 & 1.41 & 0.76 & 0.81 & 0.34 & 0.43 & 0.20 & 1.15 & 0.96 \\
\hline $\begin{array}{l}65 \text { years and older } \\
\text { (4) }\end{array}$ & 0.87 & 0.81 & $\begin{array}{l}0.05 \\
(* * *)\end{array}$ & 0.05 & 0.45 & 0.42 & 0.17 & 0.16 & 0.89 & 0.88 & 1.26 & 0.85 & 0.22 & 0.27 & 1.00 & - \\
\hline Transit mode used mos & ften & & & & & & & & & & & & & & & \\
\hline Bus (1) & 0.37 & 0.23 & 0.83 & 0.64 & 1.62 & 0.79 & 1.06 & 0.40 & 1.19 & 0.66 & 0.91 & 0.35 & 1.07 & 0.49 & 2.05 & 1.58 \\
\hline Rail (1) & 0.51 & 0.28 & 1.23 & 0.92 & 1.82 & 0.82 & 1.73 & 0.63 & 1.01 & 0.51 & 1.05 & 0.40 & 1.12 & 0.49 & 1.36 & 0.84 \\
\hline Other (1) & 0.29 & 0.24 & 0.96 & 1.06 & 1.16 & 1.14 & 2.05 & 1.46 & 0.74 & 0.71 & 0.70 & 0.49 & 1.97 & 1.67 & 0.75 & 1.50 \\
\hline Population density & 0.04 & 0.82 & $\begin{array}{c}1.5 \mathrm{E}-21 \\
(* *)\end{array}$ & $3.2 \mathrm{E}-20$ & $\begin{array}{c}4.1 \mathrm{E}- \\
27\end{array}$ & $\begin{array}{l}2.0 \mathrm{E}- \\
25\end{array}$ & 0.00 & 0.001 & 0.96 & 19.05 & $\begin{array}{l}9.2 \mathrm{E}- \\
07\end{array}$ & $1.6 \mathrm{E}-05$ & 0.77 & 14.31 & $\begin{array}{c}1.4 \mathrm{E}- \\
24\end{array}$ & $5.5 \mathrm{E}-23$ \\
\hline $\begin{array}{l}\text { Cumulative Covid-19 } \\
\text { Infection (Log) }\end{array}$ & 1.07 & 0.13 & 1.12 & 0.16 & 0.98 & 0.15 & 0.95 & 0.09 & 1.12 & 0.14 & 1.16 & 0.12 & 1.01 & 0.11 & 1.14 & 0.16 \\
\hline Constant & 7.98 & 14.62 & 6.28 & 14.37 & 0.19 & 0.44 & 1.13 & 1.66 & $\begin{array}{l}0.006 \\
(* * *)\end{array}$ & 0.01 & $\begin{array}{l}0.04 \\
(* *) \\
\end{array}$ & 0.06 & 0.13 & 0.21 & $\begin{array}{l}\mathbf{0 . 0 0 2} \\
(* * *)\end{array}$ & 0.004 \\
\hline $\mathrm{N}$ & 260 & & 280 & & 280 & & 280 & & 280 & & 281 & & & 2 & & \\
\hline Wald Chi Square & 22.04 & & 37.44 & & 30.64 & & 28.35 & & 62.95 & & 26.32 & & & & & \\
\hline Prob $>$ Chi Square & .078 & & .0006 & & .006 & & .01 & & .00 & & .02 & & & & & \\
\hline Log Pseudolikelihood & -105.59 & & -59.88 & & -109.44 & & -178.62 & & -98.04 & & -170.1 & & .01 & -14 & & \\
\hline Pseudo R Square & .09 & & .20 & & .167 & & .08 & & .31 & & .08 & .2 & & & & \\
\hline
\end{tabular}


Table 6: Logistic models of the effect of transit reductions on ability to reach essential destinations during the Covid-19 pandemic

\begin{tabular}{|c|c|c|c|c|c|c|c|c|}
\hline & \multirow{2}{*}{\multicolumn{2}{|c|}{$\begin{array}{c}\text { Model 1 } \\
\text { Work } \\
\end{array}$}} & \multirow{2}{*}{\multicolumn{2}{|c|}{$\begin{array}{l}\text { Model } 2 \\
\text { Grocery } \\
\end{array}$}} & \multirow{2}{*}{\multicolumn{2}{|c|}{\begin{tabular}{|c|} 
Model 3 \\
Healthcare
\end{tabular}}} & \multirow{2}{*}{\multicolumn{2}{|c|}{$\begin{array}{c}\text { Model } 4 \\
\text { Pharmacy }\end{array}$}} \\
\hline & & & & & & & & \\
\hline & Odds Ratio & $\begin{array}{l}\text { Robust } \\
\text { St. Err. }\end{array}$ & Odds Ratio & $\begin{array}{l}\text { Robust St. } \\
\text { Err. }\end{array}$ & Odds Ratio & $\begin{array}{l}\text { Robust St. } \\
\text { Err. }\end{array}$ & Odds Ratio & $\begin{array}{l}\text { Robust St. } \\
\text { Err. }\end{array}$ \\
\hline \multicolumn{9}{|l|}{$\begin{array}{l}\text { Dependent Variable: } \\
\text { Harder-1; Not Harder-0 }\end{array}$} \\
\hline Vehicle access (1) & 1.17 & 0.43 & 0.49 & 0.19 & 0.78 & 0.29 & 0.55 & 0.25 \\
\hline Rely on transit (1) & 1.83 & 0.60 & $3.62(* * *)$ & 1.30 & $3.78(* * *)$ & 1.34 & 2.01 & 0.86 \\
\hline Hispanic/Latinx (1) & 1.40 & 0.49 & $2.24(* *)$ & 0.80 & $2.33(* *)$ & 0.85 & $3.58(* * *)$ & 1.36 \\
\hline Female (1) & 1.24 & 0.37 & 1.27 & 0.39 & $2.30(* * *)$ & 0.69 & 1.55 & 0.55 \\
\hline Poverty status (1) & $2.13(* *)$ & 0.72 & 0.95 & 0.31 & 1.40 & 0.45 & 1.30 & 0.49 \\
\hline \multicolumn{9}{|l|}{ Age reference $(<25 \mathrm{yrs})$} \\
\hline 25-44 years old (2) & 1.80 & 0.74 & 1.16 & 0.47 & 0.83 & 0.33 & 0.52 & 0.24 \\
\hline 45-64 years old (3) & 1.74 & 0.85 & 2.03 & 0.93 & 1.09 & 0.51 & 1.08 & 0.56 \\
\hline 65 years and older (4) & .55 & 0.50 & 1.43 & 1.23 & 2.10 & 2.12 & 0.88 & 0.77 \\
\hline \multicolumn{9}{|c|}{ Transit mode used most often } \\
\hline Bus (1) & 1.27 & 0.55 & 1.62 & 0.72 & 1.17 & 0.47 & 2.18 & 1.08 \\
\hline Rail (1) & 1.17 & 0.50 & 0.93 & 0.42 & 0.91 & 0.37 & 1.99 & 0.95 \\
\hline Other (1) & 3.42 & 2.57 & 1.75 & 1.16 & 1.39 & 0.82 & 4.02 & 3.21 \\
\hline Population density & .190 & 3.34 & $1.5 \mathrm{E}-12$ & $3.1 \mathrm{E}-11$ & 72.02 & 1272.89 & $1.6 \mathrm{E}-15$ & $4.0 \mathrm{E}-14$ \\
\hline Constant & $0.16(* *)$ & 0.11 & $0.17(* *)$ & 0.12 & $0.13(* * *)$ & 0.09 & $0.09(* * *)$ & 0.08 \\
\hline $\mathrm{N}$ & 226 & & 263 & & 262 & & 251 & \\
\hline Wald Chi Square & 20.06 & & 44.10 & & 49.71 & & 50.69 & \\
\hline Prob $>$ Chi Square & .07 & & .00 & & .00 & & .00 & \\
\hline Log Pseudolikelihood & -144.21 & & -139.41 & & -141.04 & & -107.83 & \\
\hline Pseudo R Square & .06 & & .15 & & .16 & & .17 & \\
\hline
\end{tabular}


To provide more insight on impacts for a specific group of essential riders, we evaluate betweengroup differences in difficulty reaching family care and childcare destinations for those who reduced or stopped their transit use using Wilcoxon-Mann-Whitney tests (Table 7). We find that people without vehicle access, people who do not have a driver's license, Hispanic and Latinx riders, and people living under twice the poverty level reported significantly greater difficulty reaching both family care and childcare destinations due to their reduction in transit use, while those who rely on transit reported greater difficulty reaching family care destinations. It is also noteworthy that female riders reported significantly greater difficulty reaching childcare. This finding corresponds inequities in labor distributions between gender groups and their manifestation in travel patterns (Taylor et al., 2015), which has been exacerbated by pandemicrelated school and daycare closures in many regions and the "work from home era" during the Covid-19 pandemic.

Overall, our survey results highlight differences in how the pandemic has affected essential transit riders, many of whom have reduced their transit use despite their continued need to travel and their reliance on transit to reach essential destinations. Our finding that service cuts may be causing reductions in transit use among some transit riders is particularly concerning considering the current transit funding crisis. Continued transit service cuts will dramatically affect essential transit riders' day-to-day lives. Many of our survey respondents described how a loss of transit service in their neighborhood would affect them in an open-ended survey prompt. Those without alternatives indicated that the effects would be catastrophic ("I would be $100 \%$ trapped..."), noting that it would be difficult or impossible to get to work and other important destinations such as health care or groceries. Some essential riders mentioned challenges associated with 
alternatives to transit including long walking distances, spending money on rides, or obtaining rides from others. For many of these riders, the connections provided by transit are critical for meeting their day-to-day needs. 
Table 7: Between-group comparisons of the effects of transit reductions on ability to reach essential destinations by rider type (for riders who reduced or stopped using transit).

\begin{tabular}{|c|c|c|c|c|c|c|c|c|c|c|c|c|c|c|}
\hline Dependent variable & \multicolumn{2}{|c|}{ Vehicle access } & \multicolumn{2}{|c|}{ Driver's license } & \multicolumn{2}{|c|}{ Rely on transit } & \multicolumn{2}{|c|}{ Hispanic / Latinx } & \multicolumn{2}{|c|}{ Disability } & \multicolumn{2}{|c|}{ Female } & \multicolumn{2}{|c|}{ Poverty } \\
\hline Harder-1; Not Harder-0 & $\mathrm{n}$ & $\begin{array}{l}\text { z-score } \\
\text { (p value) }\end{array}$ & $\mathrm{n}$ & $\begin{array}{c}\text { z-score } \\
\text { (p value) }\end{array}$ & $\mathrm{n}$ & $\begin{array}{c}\text { z-score } \\
\text { (p value) }\end{array}$ & $\mathrm{n}$ & $\begin{array}{l}\text { z-score } \\
\text { (p value) }\end{array}$ & $\mathrm{n}$ & $\begin{array}{l}\text { z-score } \\
\text { (p value) }\end{array}$ & $\mathrm{n}$ & $\begin{array}{l}\text { z-score } \\
\text { (p value) }\end{array}$ & $\mathrm{n}$ & $\begin{array}{l}\text { z-score } \\
\text { (p value) }\end{array}$ \\
\hline Family care & 255 & $\begin{array}{c}2.59 \\
\left(0.010^{*}\right)\end{array}$ & 255 & $\begin{array}{c}3.15 \\
(0.002 *)\end{array}$ & 255 & $\begin{array}{c}-3.20 \\
\left(0.0014^{*}\right)\end{array}$ & 219 & $\begin{array}{c}-2.10 \\
(0.04 *)\end{array}$ & 236 & $\begin{array}{l}-1.77 \\
(0.08)\end{array}$ & 253 & $\begin{array}{l}-1.36 \\
(0.17)\end{array}$ & 255 & $\begin{array}{c}-3.20 \\
(0.001 *)\end{array}$ \\
\hline $\mathrm{P}\{(0)>(1)\}^{* *}$ & & 0.59 & & 0.61 & & 0.41 & & 0.42 & & 0.32 & & 0.46 & & 0.40 \\
\hline Childcare & 128 & $\begin{array}{c}2.10 \\
\left(0.03^{*}\right)\end{array}$ & 128 & $\begin{array}{c}2.31 \\
(0.02 *)\end{array}$ & 128 & $\begin{array}{l}-1.74 \\
(0.08)\end{array}$ & 111 & $\begin{array}{c}-3.60 \\
(<0.001 *)\end{array}$ & 119 & $\begin{array}{l}-1.83 \\
(0.07)\end{array}$ & 126 & $\begin{array}{c}-2.6 \\
(0.01 *)\end{array}$ & 128 & $\begin{array}{c}-3.09 \\
(0.00 *)\end{array}$ \\
\hline $\mathrm{P}\{(0)>(1)\}^{* *}$ & & 0.57 & & 0.59 & & 0.45 & & 0.37 & & 0.29 & & 042 & & 0.40 \\
\hline
\end{tabular}

*Asterisks indicate differences that are significant $(\mathrm{p} \leq 0.05)$ based on a Wilcoxon-Mann-Whitney test. 


\section{CONCLUSIONS}

The ways the different transit riders experience access to destinations and adapt to adverse circumstances vary with individual circumstances and identities. Our results indicate that essential transit riders face greater hardship when they reduce their transit use. Our finding that cuts in transit service are a factor in the decision to reduce transit use is also of concern in light of the potential for a continuing downward spiral of transit ridership and revenue. Transit service cuts will dramatically affect essential transit riders' day-to-day lives. For many of these riders, the connections to jobs, social services, and other critical destinations afforded by transit will be critical for recovering from pandemic-era economic hardship.

As of early 2021, Congress has responded (and continues to respond) to this fiscal crisis with influxes of recovery funding. Strengthening public transit connections to neighborhoods with vulnerable riders has the potential to ensure that burdens on these riders are minimized in the aftermath of Covid-19. Strengthening bus services, which provide access to a range of destination and trip types and disproportionately serve low income, Black, and Hispanic and Latinx riders, is also a promising investment strategy (Higashide, 2019).

However, short term funding injections and service changes do not address long-term underinvestment in transit that serves essential transit riders. The pandemic has exacerbated a wide array of preexisting societal challenges, from racial injustice to limited domestic production of goods that serve the national interest. The current public transit funding crisis is no different. Pandemic-related revenue declines and subsequent service cuts add to decades of chronic underinvestment in essential transit services that have been brought on by shortcomings in transit financing mechanisms. 
There are notable alternative transit funding models that are designed to support the needs of vulnerable riders. Federal subsidies for elderly, disabled, and rural transit operations provide lifeline services for these populations despite the high cost of doing so. And Congress's transit rescue packages have supported operating costs, which allows for a greater share of funds to reach bus riders than capital-heavy funding programs. In fact, when faced with tough choices about service cuts since the onset of the pandemic, many transit agencies have prioritized transit service routes and modes that serve vulnerable riders (Vock, 2020).

The pandemic has highlighted differences in the ways that different transit riders adapt to major disruptions as well as disparities in the impacts they experience. It also provides an opportunity to revisit the way that we fund transit in the long run so that we can strengthen service for those that need it most. Developing alternative transit funding models that provide robust funding for transit operations — and in particular bus service—can strengthen transit service for essential public transit riders in the short and long-term aftermath of the pandemic.

\section{ACKNOWLEDGEMENTS}

The authors acknowledge Deb Niemeier for comments on an early version of this manuscript, Brittany Antonczak, Lisa Aultman-Hall, Jesus Barajas, Jon Dowds, Sarah Grajdura, Alejandro Manga Tinoco, and Stephen Montaño for comments on the survey; and Sharwari Salvi for translating responses from Spanish and synthesizing open-ended responses. All errors are the responsibility of the authors. The Hampton K. and Margaret Frye Snell Endowed Chair in Transportation at The University of Texas at Austin provided partial support for this work. 
Declaration of interest: None.

\section{AUTHOR CONTRIBUTIONS}

QH: Conceptualization; Data curation; Methodology; Formal analysis; Software; Validation; Writing (original draft), Review \& Editing; DR: Project administration; Supervision; Conceptualization; Methodology; Resources; Validation; Writing (original draft), Review \& Editing; AK: Funding acquisition; Investigation; Supervision; Conceptualization; Methodology; Resources; Validation; Writing (original draft), Review \& Editing; MP: Conceptualization; Methodology; Resources; Validation; Writing (original draft), Review \& Editing; SL: Data curation; Software; Validation; Writing (original draft); Review \& Editing. 


\section{REFERENCES}

Adams-Prassl, A., Boneva, T., Golin, M., \& Rauh, C. (2020). Inequality in the impact of the coronavirus shock: Evidence from real time surveys. Journal of Public Economics, 189, 104245. https://doi.org/10.1016/j.jpubeco.2020.104245

Allen, J., \& Farber, S. (2019). Sizing up transport poverty: A national scale accounting of lowincome households suffering from inaccessibility in Canada, and what to do about it. Transport Policy, 74, 214-223. https://doi.org/10.1016/j.tranpol.2018.11.018

Boisjoly, G., Grisé, E., Maguire, M., Veillette, M.-P., Deboosere, R., Berrebi, E., \& El-Geneidy, A. (2018). Invest in the ride: A 14 year longitudinal analysis of the determinants of public transport ridership in 25 North American cities. Transportation Research Part A: Policy and Practice, 116, 434-445. https://doi.org/10.1016/j.tra.2018.07.005

BTS. (n.d.). Daily Vehicle Travel During the COVID-19 Public Health Emergency | Bureau of Transportation Statistics. Retrieved February 3, 2021, from https:/www.bts.gov/covid19/daily-vehicle-travel

Church, R. L., \& Marston, J. R. (2003). Measuring Accessibility for People with a Disability. Geographical Analysis, 35(1), 83-96. https://doi.org/10.1111/j.15384632.2003.tb01102.x

Cochran, A. L. (2020). Impacts of COVID-19 on access to transportation for people with disabilities. Transportation Research Interdisciplinary Perspectives, 8, 100263. https://doi.org/10.1016/j.trip.2020.100263 
Conway, M. W., Salon, D., da Silva, D. C., \& Mirtich, L. (2020). How Will the COVID-19 Pandemic Affect the Future of Urban Life? Early Evidence from Highly-Educated Respondents in the United States. Urban Science, 4(4), 50.

https://doi.org/10.3390/urbansci4040050

Dong, E., Du, H., \& Gardner, L. (2020). An interactive web-based dashboard to track COVID-19 in real time. The Lancet Infectious Diseases, 20(5), 533-534. https://doi.org/10.1016/S1473-3099(20)30120-1

Duvarci, Y., Yigitcanlar, T., \& Mizokami, S. (2015). Transportation disadvantage impedance indexing: A methodological approach to reduce policy shortcomings. Journal of Transport Geography, 48, 61-75. https://doi.org/10.1016/j.jtrangeo.2015.08.014

EBP. (2021). The Impact of the COVID-19 Pandemic on Public Transit Funding Needs in the U.S. Prepared for the American Public Transportation Association. https://www.apta.com/wp-content/uploads/APTA-COVID-19-Funding-Impact-2021-0127.pdf

Figliozzi, M., \& Unnikrishnan, A. (2021). Home-deliveries before-during COVID-19 lockdown: Accessibility, environmental justice, equity, and policy implications. Transportation Research Part D, 93. https://doi.org/10.1016/j.trd.2021.102760

Gartsman, A., \& Prescott, J. E. (2021). MBTA Ridership Trends and Projections. Massachusetts bay Transportation Authority. https://cdn.mbta.com/sites/default/files/2021-02/2021-0222-fmcb-18-ridership-trends-projections.pdf 
Gilow, M. (2020). "It's work, physically and logistically": Analyzing the daily mobility of employed mothers as Domestic Mobility Work. Journal of Transport Geography, 85, 102693. https://doi.org/10.1016/j.jtrangeo.2020.102693

Grengs, J. (2005). The abandoned social goals of public transit in the neoliberal city of the USA. City, 9(1), 51-66. https://doi.org/10.1080/13604810500050161

Grengs, J. (2015). Nonwork Accessibility as a Social Equity Indicator. International Journal of Sustainable Transportation, 9(1), 1-14. https://doi.org/10.1080/15568318.2012.719582

Handy, S. (2020). Is accessibility an idea whose time has finally come? Transportation Research Part D: Transport and Environment, 83, 102319. https://doi.org/10.1016/j.trd.2020.102319

Higashide, S. (2019). Better Buses, Better Cities: How to Plan, Run, and Win the Fight for Effective Transit (Illustrated edition). Island Press.

Hu, S., \& Chen, P. (2021). Who left riding transit? Examining socioeconomic disparities in the impact of COVID-19 on ridership. Transportation Research Part D: Transport and Environment, 90, 102654. https://doi.org/10.1016/j.trd.2020.102654

Karner, A. (2018). Assessing public transit service equity using route-level accessibility measures and public data. Journal of Transport Geography, 67, 24-32. https://doi.org/10.1016/j.jtrangeo.2018.01.005

Karner, A., \& Levine, K. (In press). Equity advancing practices at US public transit agencies. Transportation Research Record. 
Karner, A., London, J., Rowangould, D., \& Manaugh, K. (2020). From Transportation Equity to Transportation Justice: Within, Through, and Beyond the State. Journal of Planning Literature, 35(4), 440-459. https://doi.org/10.1177/0885412220927691

Karner, A., \& Niemeier, D. (2013). Civil rights guidance and equity analysis methods for regional transportation plans: A critical review of literature and practice. Journal of Transport Geography, 33, 126-134. https://doi.org/10.1016/j.jtrangeo.2013.09.017

Kwan, M.-P. (2013). Beyond Space (As We Knew It): Toward Temporally Integrated Geographies of Segregation, Health, and Accessibility. Annals of the Association of American Geographers, 103(5), 1078-1086. https://doi.org/10.1080/00045608.2013.792177

Levine, J., Grengs, J., \& Merlin, L. A. (2019). From Mobility to Accessibility: Transforming Urban Transportation and Land-Use Planning. Cornell University Press. https://www.cornellpress.cornell.edu/book/9781501716089/from-mobility-toaccessibility/

Liu, L., Miller, H. J., \& Scheff, J. (2020). The impacts of COVID-19 pandemic on public transit demand in the United States. PLOS ONE, 15(11), e0242476. https://doi.org/10.1371/journal.pone.0242476

Loukaitou-Sideris, A. (2014). Fear and safety in transit environments from the women's perspective. Security Journal, 27(2). https://doi.org/10.1057/sj.2014.9 
Lowe, K. (2014). Bypassing Equity? Transit Investment and Regional Transportation Planning. Journal of Planning Education and Research, 34(1), 30-44. https://doi.org/10.1177/0739456X13519474

Lowe, K., \& Hall, E. (2019). New Starts, Growing Inequities: Federal and Local Public Transit Funding. Public Works Management \& Policy, 24(3), 301-314. https://doi.org/10.1177/1087724X18808533

Lowe, K., Reckhow, S., \& Gainsborough, J. F. (2016). Capacity and Equity: Federal Funding Competition Between and Within Metropolitan Regions. Journal of Urban Affairs, 38(1), 25-41. https://doi.org/10.1111/juaf.12203

Lubitow, A., Abelson, M. J., \& Carpenter, E. (2020). Transforming mobility justice: Gendered harassment and violence on transit. Journal of Transport Geography, 82, 102601.

Lubitow, A., Rainer, J., \& Bassett, S. (2017). Exclusion and vulnerability on public transit: Experiences of transit dependent riders in Portland, Oregon. Mobilities, 12(6), 924-937.

Lubitow, A., Tompkins, K., \& Feldman, M. (2019). Sustainable Cycling For All? Race and Gender-Based Bicycling Inequalities in Portland, Oregon. City \& Community, 18(4), 1181-1202. https://doi.org/10.1111/cico. 12470

Lucas, K. (2012). Transport and social exclusion: Where are we now? Transport Policy, 20, 105-113. https://doi.org/10.1016/j.tranpol.2012.01.013

Martens, K. (2012). Justice in Transport as Justice in Accessibility: Applying Walzer's 'Spheres of Justice" to the Transport Sector. Transportation, 39(6), 1035-1053. eoh. http://link.springer.com/journal/volumesAndIssues/11116 
Martens, K., Golub, A., \& Robinson, G. (2012). A justice-theoretic approach to the distribution of transportation benefits: Implications for transportation planning practice in the United States. Transportation Research Part A: Policy and Practice, 46(4), 684-695. https://doi.org/10.1016/j.tra.2012.01.004

Matsuo, M. (2020). Carpooling and drivers without household vehicles: Gender disparity in automobility among Hispanics and non-Hispanics in the U.S. Transportation, 47(4), 1631-1663. https://doi.org/10.1007/s11116-019-09974-w

Palm, M., Allen, J., Liu, B., Zhang, Y., Widener, M., \& Farber, S. (2021). Riders Who Avoided Public Transit During COVID-19: Personal Burdens and Implications for Social Equity. Journal of the American Planning Association. https://doi.org/10.1080/01944363.2021.1886974

Ravensbergen, L., \& Newbold, B. (2020). “I wouldn't want to get on the bus”: Older Adult Public Transit Use and Challenges during the COVID-19 Pandemic. Findings, 18202. https://doi.org/10.32866/001c.18202

Ryvicker, M., Bollens-Lund, E., \& Ornstein, K. A. (2020). Driving Status and Transportation Disadvantage Among Medicare Beneficiaries. Journal of Applied Gerontology, 39(9), 935-943. https://doi.org/10.1177/0733464818806834

Shamshiripour, A., Rahimi, E., Shabanpour, R., \& Mohammadian, A. (Kouros). (2020). How is COVID-19 reshaping activity-travel behavior? Evidence from a comprehensive survey in Chicago. Transportation Research Interdisciplinary Perspectives, 7, 100216. https://doi.org/10.1016/j.trip.2020.100216 
Sheller, M. (2018). Mobility Justice: The Politics of Movement in an Age of Extremes. Verso.

Taylor, B. D., \& Morris, E. A. (2015). Public transportation objectives and rider demographics: Are transit's priorities poor public policy? Transportation, 42(2), 347-367. https://doi.org/10.1007/s11116-014-9547-0

Taylor, B. D., Ralph, K., \& Smart, M. (2015). What Explains the Gender Gap in Schlepping? Testing Various Explanations for Gender Differences in Household-Serving Travel. Social Science Quarterly, 96(5), 1493-1510.

Tirachini, A., \& Cats, O. (2020). COVID-19 and Public Transportation: Current Assessment, Prospects, and Research Needs. Journal of Public Transportation, 22(1). https://doi.org/10.5038/2375-0901.22.1.1

Transit \& APTA. (2020a). APTA - Ridership Trends. American Public Transit Association. transitapp.com/APTA

Transit \& APTA. (2020b). APTA - Ridership Trends. American Public Transit Association. transitapp.com/APTA

Untokening Collective. (2017). Untokening 1.0-Principles of Mobility Justice. The Untokening. http://www.untokening.org/updates/2017/11/11/untokening-10-principles-of-mobilityjustice

U.S. Census Bureau. (n.d.). 2014-2018 ACS 5-Year statistics. https://www.census.gov/acs/www/data/data-tables-and-tools/data-profiles/2018/ 
Verlinghieri, E. (2019). Learning from the grassroots: A resourcefulness-based worldview for transport planning. Transportation Research Part A: Policy and Practice. https://doi.org/10.1016/j.tra.2019.07.001

Verlinghieri, E., \& Schwanen, T. (2020). Transport and mobility justice: Evolving discussions. Journal of Transport Geography, 87, 102798. https://doi.org/10.1016/j.jtrangeo.2020.102798

Vock, D. C. (2020, December). Transit In Crisis. Planning. https://www.planning.org/planning/2020/dec/transit-in-crisis/

Voulgaris, C. T. (2020). What Is a Forecast for? Journal of the American Planning Association, 86(4), 458-469. https://doi.org/10.1080/01944363.2020.1746191

Zhang, Y., Palm, M., Scheff, J., Farber, S., \& Widener, M. (2020). Travel Survey Recruitment Through Facebook and Transit app: Lessons from COVID-19. Findings, 18066. https://doi.org/10.32866/001c.18066 